\title{
DESEMPENHO PRODUTIVO E ECONÔMICO DE FRANGOS DE CORTE SUBMETIDOS A PROGRAMAS DE RESTRIÇÃO ALIMENTAR
}

\author{
Kely Cristina Bastos Teixeira Ramos, ${ }^{1}$ Augusto Vidal da Costa Gomes, ${ }^{2}$ Cristina Amorim Ribeiro de \\ Lima, ${ }^{3}$ André Mantegazza Camargo, ${ }^{4}$ Fernado Augusto Curvello, ${ }^{5}$ Rosani Valéria Marcelina Matoso \\ Silva $^{6}$ e Priscila de Andrade Massi ${ }^{7}$
}

1. Mestranda do Programa de Pós-Graduação em Zootecnia da UFRRJ/Seropédica. E-mail:kcbtr@yahoo.com.br

2. Professor do Departamento de Nutrição Animal e Pastagens da UFRRJ/Seropédica

3. Professora do Departamento de Nutrição Animal e Pastagens da UFRRJ/Seropédica

4. Mestrando do Programa de Pós-Graduação em Zootecnia da UFRRJ/Seropédica 5. Professor do Departamento de Produção Animal da UFRRJ/Seropédica 6. Aluna de graduação em Zootecnia na UFRRJ/Seropédica 7. Zootecnista, Msc., autônoma.

\section{RESUMO}

Objetivou-se com este estudo avaliar os efeitos dos diferentes programas de restrição alimentar no desempenho produtivo e econômico de frangos de corte. Foram utilizados 264 animais, distribuídos em um delineamento inteiramente casualizado, com seis tratamentos, quatro repetições e dez aves por parcela. Os programas de restrição alimentar (RA) foram: T1 - ração à vontade; T2 - RA no $8^{\circ}$ dia de idade; T3 - RA nos $8^{\circ}$ e $13^{\circ}$ dias de idade; T4 - RA nos $8^{\circ}, 13^{\circ}$ e $18^{\circ}$ dias de idade; T5 - RA nos $8^{\circ}, 13^{\circ}, 18^{\circ}$ e $23^{\circ}$ dias de idade; T6 - RA nos $8^{\circ}, 13^{\circ}, 18^{\circ}, 23^{\circ}$ e $28^{\circ}$ dias de idade. No período total de criação, os programas de restrição alimentar não influenciaram o desempenho produtivo (consumo de ração, ganho de peso e conversão alimentar) das aves. No entanto, os frangos do T6 alcançaram menor peso vivo aos 42 dias de idade em relação aos do T1 e do T2. Em relação aos indicadores econômicos, os frangos do T1 apresentaram maior renda bruta média (RBM) e índice relativo de rentabilidade (IRR), enquanto o T6 resultou em menores valores para RBM e IRR. Considerando-se os resultados para desempenho e os indicadores econômicos obtidos no presente estudo, não foram encontradas justificativas para a adoção de programas de restrição alimentar em frangos de corte machos da linhagem Cobb.

PALAVRAS-CHAVES: Consumo de ração, conversão alimentar, ganho de peso, índice relativo de rentabilidade, machos.

\section{ABSTRACT}

\section{PRODUCTIVE AND ECONOMICAL PERFORMANCE OF BROILER CHICKENS SUBMITTED TO FEED RESTRICTION PROGRAMS}

The objective of this study was to evaluate the effects of the different quantitative feed restriction programs on the productive and economical performance of broiler chickens. Two hundred and sixty four broilers distributed in a completely randomized design, with six treatments, four replications and ten birds per replication were used. The feed restriction (FR) programs were: T1 - ad libitum; T2 $-\mathrm{FR}$ at $8^{\text {th }}$ day of age; T3 $-\mathrm{FR}$ at $8^{\text {th }}$ and $13^{\text {th }}$ days of age; T4 $-\mathrm{FR}$ at $8^{\text {th }}, 13^{\text {th }}$ and $18^{\text {th }}$ days of age;
T5 - FR at $8^{\text {th }}, 13^{\text {th }}, 18^{\text {th }}$ and $23^{\text {th }}$ days of age; T6 - FR at $8^{\text {th }}$, $13^{\text {th }}, 18^{\text {th }}, 23^{\text {th }}$ and $28^{\text {th }}$ days of age. Evaluating the total period the feed restriction program did not influence the productive performance (feed intake, feed:gain ratio and weight gain) of the birds. Nevertheless, the T6 animals reached smaller live weight at 42 days of age in relation to $\mathrm{T} 1$ and $\mathrm{T} 2$. In relation to the financial indicators, the broilers of the $\mathrm{T} 1$ presented greater average gross income (AGI) and relative profitability index (RPI) while the T6 
resulted in smaller AGI and RPI values. Considering the results to performance and economical indicators parameters presented in this study, no reasons were found to justify the adoption of feed restriction programs in male broiler chickens from Cobb strain.

KEYWORDS: Feed-gain ratio, feed intake, males, relative profitability index, weight gain.

\section{INTRODUÇÃO}

Os avanços nas áreas de melhoramento genético, nutrição, manejo, biosseguridade, entre outras, proporcionaram melhoras significativas na produção de frangos de corte. O frango moderno é caracterizado, principalmente, por sua alta taxa de crescimento e sua precocidade (PELICANO et al., 2005; RAMOS et al., 2009; AZARNIK et al. 2010).

Embora a elevada taxa de crescimento corporal seja desejável, o avanço no ganho de peso e no consumo de ração intensifica alguns problemas. Entre eles estão o aumento na deposição de gordura e as desordens ósseas e metabólicas, que levam a prejuízos no desempenho zootécnico e geram perdas econômicas (CAMACHO et al., 2004).

Diversos estudos sobre programas de manejo que limitam o rápido crescimento inicial e os problemas decorrentes dele têm mostrado que a prática da restrição alimentar é uma proposta a ser explorada.

Uma das preocupações quanto à introdução da técnica de restrição alimentar está relacionada ao ganho compensatório, pois o peso de abate é um parâmetro importante para a comercialização (FURLAN et al., 2002). Entretanto, diversos autores (FURLAN et al., 2001; SARTORI et al., 2001; TOGASHI, 2004; HASSANABADI \& MOGHADDAM, 2006) citam que o crescimento dos frangos de corte diminui no período de limitação da ingestão de alimento, ao passo que após a restrição o frango apresenta ganho de peso em relação às aves alimentadas à vontade, compensando, dessa forma, o período de restrição.

Assim, a recuperação parcial ou total do peso perdido durante a restrição alimentar dependerá da magnitude das respostas a fatores como idade, linhagem, sexo dos animais, intensidade e duração da restrição, natureza (qualitativa ou quantitativa), estresse imposto e intervalo entre o final da restrição e o abate das aves (LEU et al., 2002).

Como a restrição alimentar pode influenciar de forma negativa a velocidade de crescimento dos frangos de corte, alguns pesquisadores (ALBANEZ et al.,
2000; LANA et al., 2000) sugerem que a restrição severa no consumo - por um período curto de tempo e em idade que permita a recuperação antes da idade de abate - pode levar a um crescimento compensatório, além de reduzir o consumo de ração e, consequentemente, aumentar a viabilidade econômica.

Objetivou-se com este trabalho, portanto, avaliar os efeitos dos diferentes programas de restrição alimentar quantitativa no desempenho produtivo e econômico de frangos de corte macho da linhagem Cobb.

\section{MATERIAL E MÉTODOS}

O experimento foi conduzido no Departamento de Nutrição Animal e Pastagens (DNAP) do Instituto de Zootecnia da Universidade Federal Rural do Rio de Janeiro (UFRRJ), no município de Seropédica, RJ. O período experimental foi de 24 de julho a 3 de setembro de 2006.

As médias registradas das temperaturas mínima e máxima foram de 23,5 e $26,3{ }^{\circ} \mathrm{C}$, respectivamente, aferidas diariamente de manhã e à tarde, durante o período experimental.

Alojaram-se inicialmente 264 pintos de corte machos, de 1 dia de idade, da linhagem comercial Cobb Avian 48, distribuídos em quatro baterias metálicas com três andares, sendo cada andar subdividido em dois compartimentos $(0,90 \times 0,85 \times 0,40 \mathrm{~m})$. Cada compartimento foi provido de dois bebedouros e um comedouro tipo calha.

As aves foram pesadas após o recebimento e distribuídas nas unidades experimentais de forma que o peso vivo de cada repetição tivesse uma média semelhante (39,92 g), ficando 11 pintos por compartimento. Do $1^{\circ}$ ao $7^{\circ}$ dia de idade todas as aves receberam água e ração à vontade. No final do $7^{\circ}$ dia de idade, todas as aves foram pesadas novamente e redistribuídas, tendo em vista a equalização dos pesos corporais entre os tratamentos. Para tanto, retirou-se de cada unidade experimental 1 pinto que apresentasse maior diferença em relação ao peso médio da 
repetição $(160,43 \mathrm{~g})$, o que resultou em um total de 10 animais por unidade experimental.

No incubatório, os pintos foram vacinados contra as doenças de Marek, Gumboro e Bouba aviária. Aos doze dias de idade, as aves receberam na água de beber, vacina contra a doença de Newcastle, amostra La Sota.

O aquecimento das aves, fornecido por lâmpadas de 100 watts instaladas nas unidades experimentais foi controlado por meio de observação da disposição dos animais e de medições diárias da temperatura interna das gaiolas. $\mathrm{O}$ aquecimento foi finalizado aos doze dias de idade.

$\mathrm{O}$ peso dos animais foi registrado nos $1^{\circ}, 8^{\circ}$, $13^{\circ}, 18^{\circ}, 23^{\circ}, 28^{\circ}, 33^{\circ}, 38^{\circ}$ e $42^{\circ}$ dias de idade. Fez-se o registro do consumo de ração nos mesmos dias das pesagens, com exceção do $1^{\circ}$ dia.

O período experimental ocorreu do $8^{\circ}$ ao $42^{\circ}$ dia de idade, sendo as aves distribuídas em delineamento experimental inteiramente casualizado, com seis tratamentos e quatro repetições, em que foram impostos os seguintes programas: T1 - controle (ração à vontade); T2 - restrição alimentar de 24 horas no $8^{\circ}$ dia de idade; T3 - restrição alimentar de 24 horas nos $8^{\circ}$ e $13^{\circ}$ dias de idade; T4 - restrição alimentar de 24 horas nos $8^{\circ}, 13^{\circ}$ e $18^{\circ}$ dias de idade; T5 - res- trição alimentar de 24 horas nos $8^{\circ}, 13^{\circ}, 18^{\circ}$ e $23^{\circ}$ dias de idade; T6 - restrição alimentar de 24 horas nos $8^{\circ}$, $13^{\circ}, 18^{\circ}, 23^{\circ}$ e $28^{\circ}$ dias de idade.

As aves submetidas ao $\mathrm{T} 1$ receberam ração e água à vontade, durante todo o período experimental. Os frangos que foram submetidos aos programas de restrição alimentar permaneceram em jejum por um período de 24 horas, com início às 8 horas e término no mesmo horário do dia seguinte, e tiveram livre acesso à água.

Para verificação do desempenho zootécnico, avaliaram-se os parâmetros ganho de peso, consumo de ração, conversão alimentar e peso vivo, de acordo com as definições que seguem: $\mathrm{O}$ ganho de peso foi obtido através da diferença entre o peso inicial e o peso final de cada período. O consumo de ração foi calculado considerando-se a ração fornecida e as sobras de rações nos comedouros para cada período. Obteve-se a conversão alimentar por meio da divisão do consumo de ração e do peso das aves para cada período. O peso vivo foi obtido pelo peso médio dos frangos antes do jejum, aos 42 dias de idade.

Utilizaram-se quatro tipos de rações (Tabelas 1 e 2) formuladas para atender no mínimo as recomendações preconizadas por ROSTAGNO et al. (2005).

TABELA 1. Composição percentual das rações

\begin{tabular}{|c|c|c|c|c|}
\hline Ingredientes (\%) & 1 a 7 dias $^{*}$ & 8 a 21 dias & 22 a 33 dias & 34 a 42 dias \\
\hline Milho & 51,990 & 57,171 & 60,483 & 63,596 \\
\hline Farelo de soja & 41,215 & 36,577 & 33,340 & 30,365 \\
\hline Óleo de soja & 2,701 & 2,524 & 2,693 & 2,831 \\
\hline Fosfato bicálcico & 1,946 & 1,819 & 1,648 & 1,491 \\
\hline Calcário calcítico & 0,870 & 0,838 & 0,790 & 0,753 \\
\hline Cloreto de sódio & 0,510 & 0,489 & 0,459 & 0,434 \\
\hline DL-metionina & 0,306 & 0,197 & 0,188 & 0,169 \\
\hline L-lisina $\mathrm{HCl}$ & 0,207 & 0,090 & 0,104 & 0,119 \\
\hline Suplemento vitamínico ${ }^{1}$ & 0,100 & 0,100 & 0,100 & 0,100 \\
\hline Suplemento mineral ${ }^{2}$ & 0,100 & 0,100 & 0,100 & 0,100 \\
\hline Cloreto de colina & 0,042 & 0,042 & 0,042 & 0,042 \\
\hline Promotor de desempenho ${ }^{3}$ & 0,013 & 0,013 & 0,013 & ------ \\
\hline Coccidiostático $^{4}$ & ------ & 0,040 & 0,040 & ------ \\
\hline Total & 100 & 100 & 100 & 100 \\
\hline
\end{tabular}

${ }^{*}$ Período não experimental

1. Níveis de garantia por kg de produto: suplemento vitamínico inicial: vitamina A 1.200.000 UI, vitamina D3 2.200.000, vitamina E 30.000 mg, vitamina K3 2.500mg, vitamina B1 $2.200 \mathrm{mg}$, vitamina B2 $6.000 \mathrm{mg}$, vitamina B6 $3.300 \mathrm{mg}$, vitamina B12 $16.000 \mathrm{mcg}$, niacina $53.000 \mathrm{mg}$, ácido pantotênico $13.000 \mathrm{mg}$, biotina $110 \mathrm{mg}$, ácido fólico $1.000 \mathrm{mg}$, antioxidante $500 \mathrm{mg}$. Suplemento vitamínico final: vitamina A 1.000.000 UI, vitamina D3 1.700.000, vitamina E $20.000 \mathrm{mg}$, vitamina K3 2.000mg, vitamina B1 $2.000 \mathrm{mg}$, vitamina B2 $4.000 \mathrm{mg}$, vitamina B6 2.000 mg, vitamina B12 $10.000 \mathrm{mcg}$, niacina $20.000 \mathrm{mg}$, ácido pantotênico $10.000 \mathrm{mg}$, biotina $25 \mathrm{mg}$, ácido fólico $500 \mathrm{mg}$,

2. Suplemento mineral: selênio $250 \mathrm{mg}$, manganês $75.000 \mathrm{mg}$, zinco $70.000 \mathrm{mg}$, ferro 50.000 , cobre $8.500 \mathrm{mg}$, iodo $1.500 \mathrm{mg}$, cobalto $200 \mathrm{mg}$.

3. Promotor de desempenho: colistina $8 \%$.

4. Coccidiostático: semduramicina $5 \mathrm{~g}$. 
TABELA 2. Composição nutricional calculada das rações

\begin{tabular}{lcccc}
\hline Nutrientes & 1 a 7 dias* & 8 a 21 dias & 22 a 33 dias & 34 a 42 dias \\
\hline Energia metabolizável (kcal/kg) & 2.925 & 2.993 & 3.050 & 3.100 \\
Proteína bruta (\%) & 23,21 & 21,30 & 0,08 & 18,95 \\
Cálcio (\%) & 0,931 & 0,878 & 0,810 & 0,751 \\
Fósforo disponível (\%) & 0,466 & 0,439 & 0,405 & 0,374 \\
Sódio (\%) & 0,221 & 0,213 & 0,201 & 0,191 \\
Lisina (\%) & 1,435 & 1,227 & 1,157 & 1,094 \\
Metionina (\%) & 0,655 & 0,526 & 0,502 & 0,469 \\
Metionina + cistina (\%) & 1,019 & 0,871 & 0,833 & 0,788 \\
Treonina (\%) & 0,900 & 0,834 & 0,787 & 0,744 \\
Triptofano (\%) & 0,287 & 0,261 & 0,243 & 0,226 \\
Ácido linoleico (\%) & 2,7481 & 2,719 & 2,769 & 2,877 \\
\hline
\end{tabular}

*Período não experimental

O estudo dos indicadores econômicos dos diferentes tratamentos foi realizado a partir dos cálculos descritos por TOGASHI (2004):

Renda bruta média (RBM) - valor em reais (R\$) obtido em função do peso médio vivo (PMV) e do preço do frango $(\mathrm{PF}) \mathrm{em} \mathrm{kg}$.

$$
\mathrm{RBM}=\mathrm{PMV} \times \mathrm{PF}
$$

Custo médio de arraçoamento (CMA) - custo total relativo ao consumo de ração (CR) em todas as fases de criação em função do custo da ração em cada fase de criação.

$$
\mathrm{CMA}=(\mathrm{CR} \text { em cada fase de criação } \mathrm{x} \text { custo ração })
$$

Margem bruta média (MBM) - diferença entre a renda bruta média (RBM) e os custos com alimentação.

$$
\mathrm{MBM}=\mathrm{RBM}-\mathrm{CMA}
$$

Rentabilidade média (RM) - divisão entre a margem bruta média (MBM) e o custo médio de alimentação (CMA).

$$
\mathrm{RM}=\mathrm{MBM} / \mathrm{CMA} \times 100
$$

Índice relativo de rentabilidade (IRR) - relação entre a rentabilidade média (RM) dos tratamentos e o controle.

\section{$\mathrm{IRR}=\mathrm{RM}$ do tratamento testado/RM tratamento controle x 100}

O preço médio do quilo do frango vivo ( $\mathrm{R} \$$ $1,50)$ foi pesquisado no comércio da região do Rio de Janeiro. $O$ valor do quilo da ração $(\mathrm{R} \$ 0,556)$ foi considerado a partir dos preços dos ingredientes usados no período experimental.

Os dados obtidos foram submetidos à análise de variância, utilizando-se o programa SAS (2000) e as médias dos tratamentos comparadas pelo teste de Tukey, no nível de 5\% de significância. Seguiu-se o seguinte modelo:

$$
y_{j}=m+t_{i}+e_{j}
$$

em que: $y_{i j}$ é a i-ésima observação referente a j-ésima repetição, $j=1,2, \ldots, J(J=4)$; $m$ é a média geral; $t_{i}$ é o efeito referente ao $\mathrm{i}$-ésimo tratamento, $\mathrm{i}=1,2, \ldots, \mathrm{I}$ (I =6); $\mathrm{e}_{\mathrm{ij}}$ é o erro experimental suposto homocedástico, independente e normalmente distribuído.

\section{RESULTADOS E DISCUSSÃO}

Os resultados de desempenho de frangos de corte machos de acordo com os tratamentos e por períodos de criação (inicial: 8 a 22 dias; final: 22 a 42 dias; e total: 8 a 42 dias) estão relacionados nas Tabelass 3, 4 e 5 . 
TABELA 3. Médias do consumo de ração (g) nos períodos 8-21, 22-42 e 8-42 dias de idade de frangos de corte submetidos a diferentes programas de restrição alimentar

\begin{tabular}{lccc}
\hline Tratamentos & $8-21$ dias & $22-42$ dias & $8-42$ dias \\
\hline T1: ração à vontade & $1.165,00 \mathrm{a}$ & $3.084,20 \mathrm{a}$ & $4.249,20 \mathrm{a}$ \\
T2: RA $8^{\circ}$ dia & $1.161,13 \mathrm{a}$ & $3.116,25 \mathrm{a}$ & $4.277,38 \mathrm{a}$ \\
T3: RA $8^{\circ}, 13^{\circ}$ dias & $1.093,35 \mathrm{~b}$ & $3.129,64 \mathrm{a}$ & $4.222,99 \mathrm{a}$ \\
T4: RA $8^{\circ}, 13^{\circ}, 18^{\circ}$ dias & $1.036,05 \mathrm{c}$ & $3.110,14 \mathrm{a}$ & $4.160,09 \mathrm{a}$ \\
T5: RA $8^{\circ}, 13^{\circ}, 18^{\circ}, 23^{\circ}$ dias & - & $3.035,27 \mathrm{a}$ & $4.060,72 \mathrm{a}$ \\
T6: RA $8^{\circ}, 13^{\circ}, 18^{\circ}, 23^{\circ}, 28^{\circ}$ dias & $-3018,94 \mathrm{a}$ & $4051,69 \mathrm{a}$ \\
CV $(\%)$ & 2,55 & 2,54 & 2,45 \\
\hline
\end{tabular}

Médias seguidas da mesma letra na coluna não diferem pelo teste de Tukey $(\mathrm{P}>0,05)$.

RA: restrição alimentar.

Ao se analisar o período entre 8-21 dias de idade, nota-se que os frangos dos tratamentos com maior número de dias de restrição alimentar (T3 e T4) apresentaram menores valores de consumo de ração quando comparados aos frangos que foram submetidos a apenas a um dia de restrição (T2) e aos frangos que receberam ração à vontade durante todo o período experimental (T1). Isso indica que, nesse período, a restrição alimentar mais severa leva a um menor consumo de ração. Entretanto, não foram observadas diferenças significativas nos valores de consumo de ração entre os frangos de todos os tratamentos que foram estudados no período final (22-42 dias de idade). Esse comportamento foi mantido quando se analisou o consumo de ração durante o período total de criação (8-42 dias de idade). Assim como neste estudo, LEE \& LEESON (2001) não relataram diferenças para consumo de ração por parte dos animais submetidos aos diferentes programas alimentares. No entanto, os resultados deste trabalho discordam daqueles obtidos por URDANETA-RINCON \& LEESON (2002) que, ao estudarem a restrição quantitativa nas características de crescimento de frangos de corte, observaram que os animais alimentos à vontade tiveram maior consumo de ração $(\mathrm{P}<0,05)$ em relação àqueles submetidos à restrição de $15 \%$ da alimentação. LANA et al. (2000) e SUGETA et al. (2002), ao avaliarem o efeito da restrição alimentar sobre o desempenho de frangos de corte, observaram que a intensidade dos programas de restrição acarretava diminuição no consumo de ração.

TABELA 4. Médias de ganho de peso (g) nos períodos 8-21, 22-42 e 8-42 dias de idade de frangos de corte submetidos a diferentes programas de restrição alimentar

\begin{tabular}{lccc}
\hline Tratamentos & $8-21$ dias & $22-42$ dias & $8-42$ dias \\
\hline T1: ração à vontade & $851,80 \mathrm{a}$ & $1.746,07 \mathrm{a}$ & $2.597,87 \mathrm{a}$ \\
T2: RA $8^{\circ}$ dia & $826,90 \mathrm{a}$ & $1.722,00 \mathrm{a}$ & $2.548,90 \mathrm{a}$ \\
T3: RA $8^{\circ}, 13^{\circ}$ dias & $772,10 \mathrm{~b}$ & $1.769,10 \mathrm{a}$ & $2.541,20 \mathrm{a}$ \\
T4: RA $8^{\circ}, 13^{\circ}, 18^{\circ}$ dias & $707,24 \mathrm{c}$ & $1.791,75 \mathrm{a}$ & $2.515,13 \mathrm{a}$ \\
T5: RA $8^{\circ}, 13^{\circ}, 18^{\circ}, 3^{\circ}$ dias & - & $1.764,47 \mathrm{a}$ & $2.453,47 \mathrm{a}$ \\
T6: RA $8^{\circ}, 13^{\circ}, 18^{\circ}, 23^{\circ}, 28^{\circ}$ dias & - & $1.654,90 \mathrm{a}$ & $2.364,25 \mathrm{a}$ \\
$\mathrm{CV}(\%)$ & 3,15 & 5,42 & 4,02 \\
\hline
\end{tabular}

Médias seguidas da mesma letra na coluna não diferem pelo teste de Tukey $(\mathrm{P}>0,05)$.

RA: restrição alimentar.

Quanto ao ganho de peso, percebe-se que no período entre 8-21 dias os frangos do tratamento T3 e T4 apresentaram valores estatisticamente inferiores
$(772,10 \mathrm{~g}$ e $707,24 \mathrm{~g})$ aos dos frangos do T1 e do T2 $(851,80 \mathrm{~g}$ e $826,90 \mathrm{~g})$, mostrando que dois ou três dias de restrição implicaram em prejuízo no ganho de peso. 
O resultado encontrado no presente estudo não está de acordo com FURLAN et al. (2002), que, ao trabalharem com frangos submetidos a diferentes períodos de arraçoamento, não encontraram diferença significativa entre as médias de ganho de peso para aves aos 21 dias de idade. Do mesmo modo, ao avaliar a restrição quantitativa em frangos de corte, TOGASHI (2004) verificou que os diferentes programas alimentares não influenciaram $(\mathrm{P}>0,05)$ os ganhos de peso dos animais aos 21 dias de idade.

No período final (entre 22-42 dias de idade), não foram observadas diferenças significativas no ganho de peso dos frangos dos diferentes tratamentos estudados, sendo essa uma resposta direta ao comportamento do consumo de ração no período. Pode-se destacar que as aves do T5 e T6 - mesmo sendo submetidas, respectivamente, a restrição alimentar nos $23^{\circ}$ e $28^{\circ}$ dias - tiveram consumo de ração e ganho de peso estatisticamente iguais aos das aves do T1. Esse resultado mostra que os períodos de 19 dias para o T5 e 14 dias para o $\mathrm{T} 6$, os quais corresponderam ao intervalo entre o último dia de restrição e o final do experimento (42 dias de idade), foram suficientes para que os animais apresentassem um consumo de ração compensatório e igual ganho de peso em relação aos frangos sem restrição. Esse período é inferior ao sugerido por NOVEL et al. (2009), para quem a restrição alimentar quantitativa (75\%) em frangos de corte deve ser seguida, pelo menos, de 21 dias de realimentação, período necessário para que a aves apresentem ganho compensatório e, consequentemente, peso final semelhante ao dos frangos com consumo à vontade. ZHAN (2007) sugeriu que seriam necessários 41 dias de realimentação para que as aves conseguissem recuperar a perda de peso ocasionada pela restrição alimentar precoce.

Quando se avaliou o ganho de peso durante o período total de criação (8-42 dias de idade), verificou-se que os frangos de corte dos tratamentos 2, 3, 4, 5 e 6 alcançaram resultados estatisticamente equivalentes aos dos frangos do T1, que foram alimentados à vontade durante todo o período experimental. Percebeu-se que os animais submetidos aos diferentes programas de restrição alimentar, permanecendo de 1 dia (T2) até 5 dias (T6) sem acesso à ração, conseguiram recuperar o peso corporal e, dessa forma, apresentar um ganho compensatório suficiente para se equipararem às aves do tratamento com alimentação à vontade. ZHAN et al. (2007) e NOVEL et al. (2009), ao avaliarem a restrição alimentar quantitativa na fase inicial, também observaram a habilidade dos frangos em compensar o ganho de peso nas semanas subsequentes de realimentação.

Esses resultados contradizem com aqueles encontrados por outros autores, que reportaram perdas no peso corporal de frangos após a restrição alimentar e verificaram que, após a restrição, os animais alimentados à vontade obtiveram melhor ganho de peso em relação aos animais submetidos a restrição alimentar (MAZZUCO et al. 2000; SARTORI et al., 2001; URDANETA-RINCON \& LEESON, 2002; TOGASHI, 2004; HASSANABADI \& MOGHADDAM, 2006. De forma contrária a esses resultados, LEE \& LEESON (2001) citaram que as aves alimentadas à vontade tiveram menor ganho de peso em relação às aves submetidas a restrição alimentar, no período experimental entre 7-49 dias de idade.

TABELA 5. Médias dos valores de conversão alimentar (g/g) nos períodos 8-21, 22-42 e 8-42 dias de idade de frangos de corte submetidos a diferentes programas de restrição alimentar.

\begin{tabular}{lccc}
\hline Tratamentos & $8-21$ dias & $22-42$ dias & $8-42$ dias \\
\hline T1: ração à vontade & $1,37 \mathrm{a}$ & $1,77 \mathrm{a}$ & $1,64 \mathrm{a}$ \\
T2: RA $8^{\circ}$ dia & $1,40 \mathrm{a}$ & $1,81 \mathrm{a}$ & $1,68 \mathrm{a}$ \\
T3: RA $8^{\circ}, 13^{\circ}$ dias & $1,42 \mathrm{ab}$ & $1,77 \mathrm{a}$ & $1,66 \mathrm{a}$ \\
T4: RA $8^{\circ}, 13^{\circ}, 18^{\circ}$ dias & $1,46 \mathrm{~b}$ & $1,74 \mathrm{a}$ & $1,65 \mathrm{a}$ \\
T5: RA $8^{\circ}, 13^{\circ}, 18^{\circ}, 23^{\circ}$ dias & - & $1,73 \mathrm{a}$ & $1,66 \mathrm{a}$ \\
T6: RA $8^{\circ}, 13^{\circ}, 18^{\circ}, 23^{\circ}, 28^{\circ}$ dias & - & $1,82 \mathrm{a}$ & $1,71 \mathrm{a}$ \\
$\mathrm{CV}(\%)$ & 2,58 & 4,28 & 3,05 \\
\hline
\end{tabular}

Médias seguidas da mesma letra na coluna não diferem pelo teste de Tukey $(\mathrm{P}>0,05)$.

RA: restrição alimentar. 
Ao se analisar a conversão alimentar no período entre 8-21 dias de idade, constata-se que o aumento do número de dias de restrição alimentar resultou em piora nos valores $(\mathrm{P}<0,05)$ desse parâmetro. Contudo, esse comportamento não se manteve no período entre 22-42 dias e no período total (8-42 dias), nos quais os frangos de todos os tratamentos apresentaram valores de conversão alimentar estatisticamente semelhantes.

No período experimental entre 8-42 dias de idade, observou-se que as aves dos tratamentos 2, 3, 4, 5 e 6, submetidas aos diferentes números de dias de restrição alimentar, apresentaram valores de conversão alimentar estatisticamente semelhantes aos das aves do tratamento em que foram alimentadas à vontade. Os frangos dos tratamentos submetidos à restrição alimentar, mesmo tendo ficado de 24 horas (T2) a 120 horas (T6) sem ração, conseguiram, nos dias em que tiveram livre acesso ao alimento, ter um consumo compensatório, o que se refletiu nos resultados encontrados para conversão alimentar.

Esses resultados não estão de acordo com aqueles relatados anteriormente por autores como
MAZZUCO et al. (2000), LIPPENS et al. (2002) e TOGASHI (2004), os quais obtiveram melhores valores para conversão alimentar $(\mathrm{P}<0,05)$ para os frangos que receberam alimentação à vontade quando comparados àqueles submetidos aos demais tratamentos. No entanto, os resultados encontrados no presente estudo estão de acordo com ALBANEZ et al. (2000), FURLAN et al. (2001), SARTORI et al. (2001) e LIPPENS et al. (2002), que ao estudarem o efeito da restrição alimentar sobre o desempenho de frangos de corte não verificaram diferença para conversão alimentar ao fim do período experimental entre os frangos alimentados à vontade ou que submetidos a restrição alimentar precoce ou tardia. Entretanto, LEE \& LEESON (2001) observaram que a conversão alimentar foi pior nas aves que receberam ração à vontade, em relação aos frangos que foram limitados a ingestão de alimentos ou nutrientes.

Os valores do peso vivo ao abate e os resultados dos indicadores econômicos em relação aos programas de restrição alimentar estudados estão apresentados na Tabela 6 .

TABELA 6. Valores de peso vivo ao abate (g), renda bruta média (RBM), custo médio de arraçoamento (CMA), margem bruta média (MBM), rentabilidade média (RM) e índice relativo de rentabilidade (IRR) dos programas de restrição alimentar.

\begin{tabular}{lcccccc}
\hline Tratamentos & Peso vivo $(\mathrm{g})$ & RBM & CMA & MBM & RM & IRR \\
\hline T1 & $2.758 \mathrm{a}$ & $4,14 \mathrm{a}$ & $2,42 \mathrm{a}$ & $1,72 \mathrm{a}$ & $71,33 \mathrm{a}$ & 100 \\
T2 & $2.710 \mathrm{a}$ & $4,07 \mathrm{ab}$ & $2,43 \mathrm{a}$ & $1,63 \mathrm{a}$ & $67,23 \mathrm{a}$ & 94,27 \\
T3 & $2.702 \mathrm{ab}$ & $4,06 \mathrm{ab}$ & $2,40 \mathrm{a}$ & $1,66 \mathrm{a}$ & $69,18 \mathrm{a}$ & 96,98 \\
T4 & $2.676 \mathrm{ab}$ & $4,02 \mathrm{ab}$ & $2,38 \mathrm{a}$ & $1,65 \mathrm{a}$ & $69,69 \mathrm{a}$ & 97,71 \\
t5 & $2.614 \mathrm{ab}$ & $3,93 \mathrm{ab}$ & $2,31 \mathrm{a}$ & $1,62 \mathrm{a}$ & $70,02 \mathrm{a}$ & 98,16 \\
T6 & $2.542 \mathrm{~b}$ & $3,79 \mathrm{~b}$ & $2,31 \mathrm{a}$ & $1,48 \mathrm{a}$ & $64,17 \mathrm{a}$ & 89,92 \\
CV(\%) & 3,78 & 3,76 & 2,42 & 7,62 & 7,33 & \\
\hline
\end{tabular}

Médias seguidas da mesma letra na coluna não diferem pelo teste de Tukey $(\mathrm{P}>0,05)$.

Pode ser observado na característica peso vivo ao abate, que as aves dos tratamentos $2,3,4$ e 5, submetidas a diferentes programas de restrição alimentar, não diferiram estatisticamente dos frangos do T1 (sem restrição). No entanto, a restrição alimentar mais severa aos frangos no T6, levou a um menor peso vivo (2.524 g) aos 42 dias de idade. Esse resultado não está de acordo com os achados por LEONE et al. (2001), que ao estudarem a in- fluência da restrição alimentar proteica e energética não observaram diferença no peso vivo aos 42 dias de idade. LANA et al. (2000) citaram que os animais que receberam ração à vontade e os animais que foram submetidos a dois dias de restrição $\left(8^{\circ}\right.$ e $10^{\circ}$ dias de idade) não obtiveram peso ao abate semelhante estatisticamente, diferentemente dos demais frangos que foram submetidos a programas de restrição alimentar mais severo. 
Os valores de renda bruta média dos programas de restrição alimentar foram influenciados significativamente $(\mathrm{P}<0,05)$. O T1 apresentou melhor renda, enquanto o t6 mostrou os piores resultados. Isso ocorreu devido aos resultados obtidos para peso vivo, o qual tem participação marcante nos procedimentos de cálculo dessa variável.

Os valores do custo médio de arraçoamento e da margem bruta média não apresentaram variações estatísticas significativas $(\mathrm{P}>0,05)$. Esse fato pode ser explicado, em parte, pelo consumo compensatório oferecido aos frangos submetidos aos diversos programas de restrição alimentar.

A rentabilidade média também não foi influenciada estatisticamente $(\mathrm{P}>0,05)$ pelos programas de restrição alimentar adotados. Para o cálculo do índice relativo de rentabilidade os frangos alimentados à vontade (T1) foram tomados como referência, e, por isso, o valor considerado para esse tratamento foi de 100 . Ao se analisarem os índices relativos de rentabilidade verificou-se que o T6, teve a restrição alimentar mais severa, resultou no pior índice, enquanto o melhor índice foi obtido pela adoção da alimentação à vontade durante todo o período de criação (T1).

A análise dos indicadores econômicos apontou que a restrição alimentar influenciou negativamente nos resultados. Sua adoção por esse critério não é, portanto, indicada.

\section{CONCLUSÕES}

Os frangos submetidos aos programas de restrição alimentar dos tratamentos 2, 3, 4, 5 e 6 apresentaram consumo de ração e ganho de peso compensatório.

Considerados os resultados para desempenho e os indicadores econômicos obtidos no presente estudo, não foram encontradas justificativas para a adoção de programas de restrição alimentar em frangos de corte machos da linhagem Cobb.

\section{REFERENCIAS}

ALBANEZ, J. R.; FONSECA, J. B.; SILVA, M. A.; SOARES, R. T. R. N.; COSTA, F. A.; SOARES, P. R. Efeito da restrição alimentar sobre o desempenho produtivo e a qualidade da carcaça de frangos de corte. Revista Brasileira de Zootecnia, v. 26, n. 6, p. $1.727-1.734,2000$.
AZARNIK, A.; BOJARPOUR, M.; ESLAMI, M.; GHORBANI, M. R.; MIRZADEH, K. The effect of different levels of diet protein on broilers performance in ad libitum and feed restriction methods. Journal of Animal and Veterinary, v. 9, n. 3, p. 631-634, 2010.

CAMACHO, M. A.; SUÁREZ, M. E.; HERRERA, J. M.; GARCIA-BOJALIL, C. M. Effect of age of feed restriction and microelement supplementation to control ascites on production and carcass characteristics of broilers. Poultry Science, v. 83, p. 526-532, 2004.

FURLAN, R. L.; CARVALHO, N. C.; MALHEIROS, E. B.; MACARI, M. Efeito da restrição alimentar inicial e da temperatura ambiente sobre o desenvolvimento de vísceras e ganho compensatório em frangos de corte. Arquivo Brasileiro de Medicina Veterinária e Zootecnia, v. 53, n. 4, p. 1-7, 2001.

FURLAN, R. L.; MACHADO, J. G. C. F.; GIACHETTO, P. F.; MALHEIROS, E. B.; FURLAN, L. R.; MACARI, M. Desempenho e composição de carcaça de frangos submetidos a diferentes períodos de arraçoamento. Revista Brasileira de Zootecnia, v. 31, n. 6, p. 2.265-2.273, 2002.

HASSANABADI, A.; MOGHADDAM, H. N. Effect of early feed restriction on performance characteristics and serum thyroxin of broiler chicken. International Journal of Poultry Sciences, v. 5, n. 12, p. 1.156-1.159, 2006.

LANA, G. R. Q.; ROSTAGNO, H. S.; ALBINO, L. F. T.; LANA, A. M. Q. Efeito da temperatura ambiente e da restrição alimentar sobre o desempenho e a composição da carcaça de frangos de corte. Revista Brasileira de Zootecnia, v. 29, n. 4, p. 1.117-1.123, 2000.

LEE, K. H.; LEESON, S. Performance of broilers fed limited quantities of feed or nutrients during seven to fourteen days of age. Poultry Science, v. 80, p. 446-454, 2001.

LEONE, E. R.; BERNAL, F. E. M.; FURLAN, R. L; MALHEIROS, E. B.; MACARI, M. Efeitos da restrição alimentar protéica ou energética sobre o crescimento de frangos de corte criados em diferentes temperaturas ambiente. Revista Brasileira de Zootecnia, v. 30, n. 3, p. 1.058-1.064, 2001.

LEU, W. M. K.; COTTA, J. T. B.; OLIVEIRA, A. I. G.; RODRIGUES, P. B. Desempenho de frangos submetidos à restrição alimentar na fase inicial em diferentes sistemas de criação. Revista Ciência Agrotécnica, v. 26, n. 3, p. 610-617, 2002.

LIPPENS, M.; HUYGHEBAERT, G.; GROOTE, G. The efficiency of nitrogen retention during compensatoty growth of food-restricted broilers. British Poultry Science, v. 43, p. 669-676, 2002.

MAZZUCO, H.; GUIDONI, A. L.; JAENISCH, F. R. Efeito da restrição alimentar qualitativa sobre o ganho compensatório em frangos de corte. Pesquisa Agropecuária Brasileira, v. 35, n. 3, p. 543-549, 2000. 
NOVEL, D. J.; NGAMBI, J. W.; NORRIS, D.; MBAJIORGU, C. A. Effect different regimes during the starter estage on productivity and carcass characteristics of male and female Ross 308 broiler chickens. International Journal of Poultry Sciences, v. 8, n. 1, p. 35-39, 2009.

PELICANO, R. L.; BERNAL, F. E. M.; FURLAN, R. L.; MALHEIROS, E. B.; MACARI, M. Efeito da temperatura ambiente e da restrição alimentar protéica ou energética sobre o ganho de peso e crescimento ósseo de frangos de corte. Arquivo Brasileiro Medicina Veterinária e Zootecnia, v. 57, n. 3, p. 353-360, 2005.

RAMOS, K. C. B. T.; GOMES, A. V. C.; CAMARGO, A. M.; LIMA, C. A. R.; OLIVEIRA, E. C. D.; OLIVEIRA, A. A.; SANTOS, V. M.; MASSI, P. A. Características da carcaça e composição química dos cortes nobres de frangos de corte submetidos a programas de restrição alimentar. Revista Ciências da Vida, v. 29, n. 1, p. 28-38, jan.-jun. 2009.

ROSTAGNO, H. S.; ALBINO, L. F. T.; DONZELE, J. L.; GOMES, P. C.; OLIVEIRO, R. F.; LOPES, D. C.; FERREIRA, A. S.; BARRETO, S. L. T. Composição de alimentos e exigências nutricionais de aves e suínos: tabelass brasileiras. Viçosa, 2. ed. MG: UFV, 2005. 141 p.

SARTORI, J. R.; GONZALES, E.; PAI, V. D.; OLIVEIRA, H. N.; MACARI, M. Efeito da temperatura ambiente e da restrição alimentar sobre o desempenho e a composição de fibras musculares esqueléticas de frangos de corte. Revista Brasileira de Zootecnia, v. 30, n. 6, p. 1.779-1.790, 2001.

STATISTICAL ANALYSES SYSTEM - SAS. SAS guide statistics. Version 6. 12 ed. Cary: SAS, 2000.

SUGETA, S. M.; GIACHETTO, P. F.; MALHEIROS, E. B.; MACARI, M.; FURLAN, R. L. Efeito da restrição alimentar quantitiva sobre o ganho compensatório e composição da carcaça de frangos. Pesquisa Agropecuária Brasileira, v. 37, n. 7, p. 903-908, jul. 2002.

TOGASHI, C. K. Teores de colesterol e ácidos graxos em tecidos e soro de frangos de corte submetidos a diferentes programas nutricionais. 2004. 97 f. Tese (Doutorado em Zootecnia) - UENF/ RJ, Campos dos Goytacazes, 2004.

URDANETA-RINCON, M.; LEESON, S. Quantitative and qualitative feed restriction on growth characteristics of male broiler chickens. Poultry Science, v. 81, p. 679-688, 2002.

ZHAN, X. A.; WANG, M.; REN, H.; ZHAO, R. Q.; LI, J. X.; TAN, Z. L. Effect of early feed restriction on metabolic programming and compensatory growth in broiler chickens. Poultry Sciences, v. 86, n. 1, p. $654-660,2007$.

Protocolado em: 13 dez. 2007. Aceito em: 29 nov. 2010. 